Pacific Journal of Mathematics

COMPOSANTS OF HAUSDORFF INDECOMPOSABLE 


\title{
COMPOSANTS OF HAUSDORFF INDECOMPOSABLE CONTINUA; A MAPPING APPROACH
}

\author{
David P. Bellamy
}

\begin{abstract}
"Continuum" denotes a compact connected Hausdorff space. The principal result is that every indecomposable continuum can be mapped onto Knaster's example $D$ of a chainable indecomposable continuum with one endpoint. This result is then used to conclude that those indecomposable continua each of whose proper subcontinua is decomposable, those which are homeomorphic with each of their nondegenerate subcontinua, and those such that each two points in the same composant can be joined by a continuum which cannot be mapped onto $D$, have at least $c$ composants. It is also shown that generalized arcwise connected continua are decomposable.
\end{abstract}

The author [1] and [2], among others, has raised the question of how many composants an indecomposable continuum must have. The technique applied to prove that metric indecomposable continua have uncountably many depends upon the second countability of the complement of a point. (See, for example, [5, p. 140].) Other arguments can generalize this; for example, $\mathrm{H}$. Cook has pointed out in conversation that if an indecomposable continuum has two composants, and is first countable at a point of each, then it has uncountably many composants. This can be generalized to include the case of a continuum with two composants, each of which contains a compact $G_{o}$ subset. S. Mazurkiewicz [7] has shown that a metric indecomposable continuum has $c$ composants, sharpening slightly the result that it has uncountably many. M. E. Rudin [10] has shown that if the continuum hypothesis holds, then it is not true that every indecomposable continuum has $c$ composants.

J. W. Rogers, Jr., [9] has shown that every metric indecomposable continuum can be mapped onto the continuum $D$ mentioned above. (See [5, p. 332] or [6, p. 206] for a picture.) We follow Rogers here in a representing $D$ as an inverse limit of arcs $[0,1]=I$, indexed by the positive integers, where the bonding map between successive terms is always $h$, where $h(t)=2 t$ for $t \leqq 1 / 2$ and $h(t)=2-2 t$ for $t \geqq 1 / 2$. Throughout what follows, let $I$ denote $[0,1] ; h$, this function; and $D$, the inverse limit of this system. This work extends Rogers' result to the nonmetric case; also, the argument here is simpler than Rogers'. This result is then applied to obtain a partial answer to the composant question in certain cases. This work also generalizes work of G. R. Gordh, Jr., presented at the University of Oklahoma Conference on General Topology in March, 1972, [3], and answers in the negative 
the question of L. E. Ward, Jr., [11], concerning whether there are indecomposable continua each two points of which can be connected by a generalized arc. (A generalized arc is a continuum with exactly two noncutpoints.)

Principal Result. We first establish the following:

Lemma. If $X$ is an indecomposable continuum and $f: X \rightarrow I$ is a continuous function such that $f^{-1}(0)$ and $f^{-1}(1)$ both have nonempty interior, then there exists a continuous function $g: X \rightarrow I$ such that $g^{-1}(0)$ and $g^{-1}(1)$ both have nonempty interior, and such that $f=h \circ g$.

Proof. Suppose $f$ is given. Let $M \cup N$ be a separation of $X$ Int $f^{-1}(1)$ such that both $M \cap \operatorname{Int} f^{-1}(0)$ and $N \cap \operatorname{Int} f^{-1}(0)$ are nonvoid. Such a separation exists since $X$-Int $f^{-1}(1)$ is compact and no component of it has interior; in particular, Int $f^{-1}(0)$ must meet at least two components and hence two quasi-components of it. Now define $g: X \rightarrow$ $I$ by

$$
\begin{aligned}
g(x) & =\frac{1}{2} f(x) \text { if } x \in M \\
& =1-\frac{1}{2} f(x) \text { if } x \in N \\
& =\frac{1}{2} \text { if } x \in f^{-1}(1) .
\end{aligned}
$$

It is readily verified that $g$ is well-defined and continuous. Then,

$$
\begin{aligned}
& \text { Int } g^{-1}(1)=N \cap \operatorname{Int} f^{-1}(0) \neq \phi \\
& \text { Int } g^{-1}(0)=M \cap \operatorname{Int} f^{-1}(0) \neq \phi .
\end{aligned}
$$

The reader can easily verify that $f=h \circ g$.

Corollary to Proof. If $X$ is an indecomposable continuum and $f: X \rightarrow I$ is a continuous function such that $f^{-1}(0)$ and $f^{-1}(1)$ both have nonempty interior, and if $p, q \in X$ are points such that $p \in \operatorname{Int} f^{-1}(0)$; $f(q) \neq 0,1$ and $q$ lies in a different component of $X$-Int $f^{-1}(1)$ from $p$, then there exists a continuous function $g: X \rightarrow I$ such that $f=h \circ g$; $g^{-1}(0)$ and $g^{-1}(1)$ both have nonempty interior, $p \in \operatorname{Int} g^{-1}(0)$, and $1>$ $g(q) \geqq 1 / 2$.

Proof. Choose $M$ and $N$ as in the proof of the lemma, so that $p \in M$. If $q \in N$, set $M^{\prime}=M ; N^{\prime}=N$. If $q \in M$, then since $p$ and $q$ lie in different components of $M$ and $M$ is compact, there is separation $M^{\prime} \cup A$ of $M$ with $q \in A$ and $p \in M^{\prime}$. Then, let $N^{\prime}=A \cup N$. In either case, proceed as in the proof of the lemma, replacing $M$ and $N$ by $M^{\prime}$ 
and $N^{\prime}$ respectively. It is then readily verified that $1>g(q) \geqq 1 / 2$ and $p \in \operatorname{Int} g^{-1}(0)$.

We are now in a position to prove:

THEOREM. Let $X$ be a nondegenerate indecomposable continuum. Then $X$ can be mapped continuously onto $D$.

Proof. Let $O$ be a nonempty open subset of $X$ such that $\mathrm{Cl}(O) \neq$ $X$. Since $\mathrm{Cl}(O)$ is a proper closed subset of an indecomposable continuum, with nonvoid interior, it is not connected. Let $A \cup B$ be a separation of $\mathrm{Cl}(0)$ and observe that both $A$ and $B$ have interior. Let $f_{1}: X \rightarrow I$ be a Urysohn function such that $f_{1}(x)=0$ for $x \in A$ and $f_{1}(x)=1$ for $x \in B$. Now, Int $f_{1}^{-1}(0) \neq \phi \neq \operatorname{Int} f_{1}^{-1}(1)$. We proceed inductively. Suppose continuous functions $f_{i}: X \rightarrow I$ have been chosen for $1 \leqq i<n$, such that for each $i>1, h \circ f_{i}=f_{i-1}$ and such that for each $i, f_{i}^{-1}(0)$ and $f_{i}^{-1}(1)$ both have interior. Applying the lemma, we obtain a function $f_{n}: X \rightarrow I$ such that $f_{n}^{-1}(0)$ and $f_{n}^{-1}(1)$ both have interior and $h \circ f_{n}=f_{n-1}$.

Then the sequence of functions $\left\langle f_{i}\right\rangle_{i=1}^{\infty}$ induces a map $f: X \rightarrow D$ which is onto since $X$ is compact and each $f_{i}$ is onto, and the proof is complete.

Before looking at the composant question, we sharpen this result somewhat with three corollaries to the proof, and to the theorem.

COROLLARY 1. If $p$ and $q$ are distinct points of the indecomposable continuum $X$, there is a continuous surjection $f: X \rightarrow D$ such that $f(p) \neq f(q)$.

Proof. Choose $O$ so that $p \in 0$ and $q \notin \mathrm{Cl}(O)$. Choose $A, B$ so that $p \in A$. Apply Tietze's extension theorem to obtain a function $f_{1}$ such that $f_{1}(x)=0$ for $x \in A, f_{1}(x)=1$ for $x \in B$, and $f_{1}(q)=1 / 2$. Then proceed as in the proof of the theorem. $f(p) \neq f(q)$ since $f_{1}(p)=0$ while $f_{1}(q)=1 / 2$.

Corollary 2. A nondegenerate indecomposable continuum $X$ can be embedded into a product of copies of $D$ such that every projection carries the image of $X$ onto $D$.

Proof. Let $F=\{f: f$ is continuous mapping of $X$ onto $D\}$. Define $k: X \rightarrow \Pi_{f \in F} D$ by $k_{f}=f$. By Corollary $1, k$ is $1-1$ and by compactness it is an embedding. The $f$-projection of $k(X)$ into $D$ yields $f(X)$, which is all of $D$.

Corollary 3. If $p$ and $q$ belong to different composants of the 
indecomposable continuum $X$, there is a continuous mapping $f: X \rightarrow D$ such that $f(p)$ and $f(q)$ lie in different composants of $D$.

Proof. Obtain $f_{1}$ as in the proof of Corollary 1. Then suppose $f_{i}$ has been chosen for $1 \leqq i<n$ such that $p \in \operatorname{Int} f_{i}^{-1}(0)$ and such that $1>f_{i}(q) \geqq 1 / 2$ for each $i$, in addition to the other properties assumed in the proof of the theorem. Then, since $p$ and $q$ lie in different composants of $X$, they must lie in different components of $X$-Int $f_{n-1}^{-1}(1)$. The corollary to the proof of the Lemma enables us to choose $f_{n}$ so that $p \in \operatorname{Int} f_{n}^{-1}(0)$ while $1>f_{n}(q) \geqq 1 / 2$. Then with the map $f: X \rightarrow$ $D$ so obtained, suppose $W \subseteq D$ were a proper subcontinuum with $f(p) \epsilon$ $W$ and $f(q) \in W$. Let $W_{i} \subseteq I$ be the $i$ th projection of $W$. Since $f(p)$ is the point each of whose coordinates is zero, $0 \in W_{i}$ for each $i$. Since $W \neq D$, there is a $j$ such that $W_{j} \neq I$. Then $1 \notin W_{j}$. Since $h(1 / 2)=$ $1,1 / 2 \notin W_{j+1}$. Thus $W_{j+1} \subseteq[0,1 / 2)$ while $f_{j+1}(q) \geqq 1 / 2$, a contradiction, since $f_{j+1}(q) \in W_{j+1}$. Hence, $f(p)$ and $f(q)$ belong to different composants of $D$.

The Composant Problem. The theorem of the preceding section now allows us to make some observations about composants and other internal structures of indecomposable continua.

Definition 1. If $X$ and $Y$ are continua and $f: X \rightarrow Y$ is a continuous surjection, $f$ maps $X$ irreducibly onto $Y$ iff $f(W)$ is a proper subcontinuum of $Y$ whenever $W$ is a proper subcontinuum of $X$.

Proposition. If $X$ and $Y$ are indecomposable continua and $f: X \rightarrow$ $Y$ irreducibly onto, then $X$ has at least as many composants as $Y$.

Proof. If $p, q$ lie in the same composant of $X$, there is a proper subcontinuum $W$ of $X$ containing $p$ and $q$. Hence, $f(W)$ is a proper subcontinuum of $Y$ containing both $f(p)$ and $f(q)$, which thus lie in the same composant of $Y$. Thus, if $K$ is a composant of $Y, f^{-1}(K)$ is a union of composants of $X$. Applying the axiom of choice, we can define a 1-1 function $g$ from the set of composants of $Y$ into the set of composants of $X$ by choosing $g(K)$ to be some composant of $X$ contained in $f^{-1}(K)$ for each composant $K$ of $Y$.

Corollary 4. If an indecomposable continuum $X$ can be mapped irreducibly onto $D, X$ has at least c composants.

Corollary 5. If $X$ is a nondegenerate indecomposable continuum, $X$ contains an indecomposable subcontinuum $M$ with at least c composants. 


\section{Proof. Let $f: X \rightarrow D$ be onto. Consider $\{W \subseteq X: W$ is a continuum and $f(W)=D\}$.}

By compactness and Zorn's lemma, this set contains a minimal element $M$; $M$ is necessarily indecomposable, and $f \mid M: M \rightarrow D$ maps $M$ irreducibly onto $D$. We are done by Corollary 4 .

DeFinition 2. An indecomposable continuum is irreducibly indecomposable iff each of its nondegenerate proper subcontinua is decomposable.

DEFINITION 3. A continuum is hereditarily equivalent iff it is homeomorphic with each of its nondegenerate subcontinua. (See [8] and [4].)

Corollary 6. An irreducibly indecomposable continuum $X$ which is nondegenerate has at least c composants.

Proof. The $M$ in Corollary 5 must in this case be $X$.

COROLlary 7. A nondegenerate hereditarily equivalent indecomposable continuum $X$ has at least c composants.

Proof. The $M$ in Corollary 5 is in this case homeomorphic with $X$ and so has the same number of composants as $X$.

We also obtain the following somewhat more technical results.

Corollary 8. If $X$ is a nondegenerate indecomposable continuum such that whenever $p, q$ belong to the same composant of $X, p$ and $q$ lie together in a continuum $W(p, q)$ which cannot be mapped onto $D$, then $X$ has at least c composants.

Proof. Let $f: X \rightarrow D$ be onto and let $M \cong X$ be a continuum such that $f(M)=D$. Suppose $M \neq X$. Then $M$ lies in some composant $K$ of $X$. Let $p, q \in M$ such that $f(p)$ and $f(q)$ belong to different composants of $D$. There is a continuum $W(p, q)$ which cannot be mapped onto $D$, while $p, q \in W(p, q)$. Then $f(W(p, q))$ is a proper subcontinuum of $D$ meeting two composants of $D$, a contradiction. Thus, $M=X$ and by Proposition 1, the proof is done.

In particular, then, if each two points of each composant of an indecomposable continuum lie in a continuum which is locally connected; is a union of fewer than $c$ locally connected continua; or is hereditarily decomposable, then the continuum has at least $c$ composants. (The hereditarily decomposable case was pointed out by L. E. Rogers and 
G. R. Gordh, Jr., in conversation with the author.)

Corollary 9. A continuum $X$, each two points of which can be joined by a continuum which cannot be mapped onto $D$, is decomposable.

Proof. Such a continuum cannot be mapped onto $D$, for if $p, q \epsilon$ $X$ and $f: X \rightarrow D$ is onto; and $f(p)$ and $f(q)$ lie in different composants of $D$, then each continuum containing both $p$ and $q$ is mapped onto $D$ by $f$.

Corollary 10. A continuum each two points of which can be joined by a generalized arc is decomposable.

The following Corollaries resolve the question in [11], mentioned earlier. We close with them.

CoROLLARY 11. A hereditarily unicoherent generalized arcwise connected continuum is hereditarily decomposable.

Proof. If $X$ is such a continuum and $W \subseteq X$ is a subcontinuum, then for any $p, q$ in $W$ there is a generalized arc $A$ in $X$ from $p$ to $q$. By irreducibility of $A$ and hereditary unicoherence, $A \subseteq W$. Thus $W$ is generalized arcwise connected and hence decomposable.

COROLLARY 12. Each generalized arcwise connected hereditarily unicoherent continuum has the fixed point property for continuous multi-valued functions.

REMARK. This is a restatement of Theorem 2 of [11, p. 926] in light of Corollary 11.

\section{REFERENCES}

1. D. P. Bellamy, A non-metric indecomposable continuum, Duke Math. J., 38, No. 1 (1971), 15-20.

2. - Topological Properties of Compactifications of Half-Open Interval., Ph. D. Thesis, Michigan State University, (1968).

3. G. R. Gordh, Jr., Indecomposable Hausdorff Continua and Mappings of Connected Linearly Ordered Spaces, presented to the University of Oklahoma Conference on General Topology, March, 1972.

4. G. W. Henderson, Proof that every compact decomposable continuum which is topologically equivalent to each of its nondegenerate subcontinua is an arc, Annals of Math., 72, No. 3 (1960), 421-428.

5. J. G. Hocking and G. S. Young, Topology, Addison-Wesley, Reading, Mass., (1969).

6. K. Kuratowski, Topology, Vol. II, Academic Press, New York and London, (1968).

7. S. Mazurkiewicz, Sur les Continus Indécomposables, Fund. Math., 10 (1927), 305-310. 
8. E. E. Moise, An indecomposable plane continuum which is homeomorphic to each of its nondegenerate subcontinua, Trans. Amer. Math. Soc., 63 (1948), 581-594.

9. J. W. Rogers, Jr., On mapping indecomposable continua onto certain chainable indecomposable continua, Proc. Amer. Math. Soc., 25. No. 2 (1970), 449-456.

10. M. E. Rudin, Composants and $\beta N$, Proceedings of the Washington State University Conference on General Topology, (1970), 117-119.

11. L. E. Ward, Jr., A fixed point theorem for multi-valued functions, Pacific J. Math., 8 (1958), 921-927.

Received June 21, 1972 and in revised form August 30, 1972.

UNiversity of Delaware 



\section{PACIFIC JOURNAL OF MATHEMATICS}

\section{EDITORS}

D. Gilbarg AND J. MILGRAM

Stanford University

Stanford, California 94305

\section{R. A. Beaumont}

University of Washington

Seattle, Washington 98105

\section{J. DUGUNDJI*}

Department of Mathematics University of Southern California Los Angeles, California 90007

RICHARD ARENS

University of California Los Angeles, California 90024

\section{ASSOCIATE EDITORS}
E. F. BECKENBACH
B. H. NEUMANN
F. WOLF
K. YoshidA

\section{SUPPORTING INSTITUTIONS}

\author{
UNIVERSITY OF BRITISH COLUMBIA \\ CALIFORNIA INSTITUTE OF TECHNOLOGY \\ UNIVERSITY OF CALIFORNIA \\ MONTANA STATE UNIVERSITY \\ UNIVERSITY OF NEVADA \\ NEW MEXICO STATE UNIVERSITY \\ OREGON STATE UNIVERSITY \\ UNIVERSITY OF OREGON \\ OSAKA UNIVERSITY
}

\author{
UNIVERSITY OF SOUTHERN CALIFORNIA \\ STANFORD UNIVERSITY \\ UNIVERSITY OF TOKYO \\ UNIVERSITY OF UTAH \\ WASHINGTON STATE UNIVERSITY \\ UNIVERSITY OF WASHINGTON \\ AMERICAN MATHEMATICAL SOCIETY \\ NAVAL WEAPONS CENTER
}

The Supporting Institutions listed above contribute to the cost of publication of this Journal, but they are not owners or publishers and have no responsibility for its content or policies.

Mathematical papers intended for publication in the Pacific Journal of Mathematics should be in typed form or offset-reproduced, (not dittoed), double spaced with large margins. Underline Greek letters in red, German in green, and script in blue. The first paragraph or two must be capable of being used separately as a synopsis of the entire paper. Items of the bibliography should not be cited there unless absolutely necessary, in which case they must be identified by author and Journal, rather than by item number. Manuscripts, in duplicate if possible, may be sent to any one of the four editors. Please classify according to the scheme of Math. Rev. Index to Vol. 39. All other communications to the editors should be addressed to the managing editor, Richard Arens, University of California, Los Angeles, California, 90024.

50 reprints are provided free for each article; additional copies may be obtained at cost in multiples of 50 .

The Pacific Journal of Mathematics is issued monthly as of January 1966. Regular subscription rate: $\$ 48.00$ a year (6 Vols., 12 issues). Special rate: $\$ 24.00$ a year to individual members of supporting institutions.

Subscriptions, orders for back numbers, and changes of address should be sent to Pacific Journal of Mathematics, 103 Highland Boulevard, Berkeley, California, 94708.

PUBLISHED BY PACIFIC JOURNAL OF MATHEMATICS, A NON-PROFIT CORPORATION

Printed at Kokusai Bunken Insatsusha (International Academic Printing Co., Ltd.), 270, 3-chome Totsuka-cho, Shinjuku-ku, Tokyo 160, Japan.

* C. DePrima will replace J. Dugundji until August 1974.

Copyright (C) 1973 by

Pacific Journal of Mathematics

All Rights Reserved 


\section{Pacific Journal of Mathematics}

\section{Vol. 47, No. $2 \quad$ February, 1973}

David Parham Bellamy, Composants of Hausdorff indecomposable continua; a mapping approach ........................ 303

Colin Bennett, A Hausdorff-Young theorem for rearrangement-invariant spaces ...........................................

Roger Daniel Bleier and Paul F. Conrad, The lattice of closed ideals and $a^{*}$-extensions of an abelian l-group ...

Ronald Elroy Bruck, Jr., Nonexpansive projections on subsets of Banach

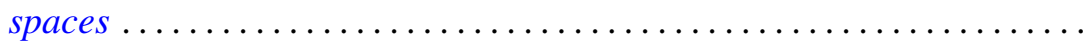

Robert C. Busby, Centralizers of twisted group algebras ............. 357

M. J. Canfell, Dimension theory in zero-set spaces ................ 393

John Dauns, One sided prime ideals ........................ 401

Charles F. Dunkl, Structure hypergroups for measure algebras . . . . . . . . . 413

Ronald Francis Gariepy, Geometric properties of Sobolev mappings ...... 427

Ralph Allen Gellar and Lavon Barry Page, A new look at some familiar spaces of intertwining operators ...........................

Dennis Michael Girard, The behavior of the norm of an automorphism of the

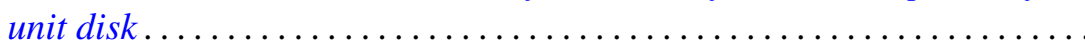

George Rudolph Gordh, Jr., Terminal subcontinua of hereditarily

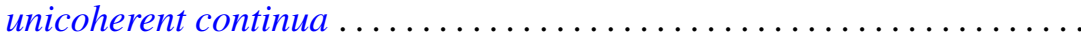

Joe Alston Guthrie, Mapping spaces and cs-networks. .

Neil Hindman, The product of $F$-spaces with $P$-spaces . 473

M. A. Labbé and John Wolfe, Isomorphic classes of the spaces $C_{\sigma}(S)$

Ernest A. Michael, On k-spaces, $k_{R}$-spaces and $k(X) \ldots$

Donald Steven Passman, Primitive group rings .

C. P. L. Rhodes, A note on primary decompositions of a pseudovaluation ...

Muril Lynn Robertson, A class of generalized functional differential equations

Ruth Silverman, Decomposition of plane convex sets. $I$.

Ernest Lester Stitzinger, On saturated formations of solvable Lie algebras................................

B. Andreas Troesch, Sloshing frequencies in a half-space by Kelvin inversion ...

L. E. Ward, Fixed point sets .

Michael John Westwater, Hilbert transforms, and a problem in scattering

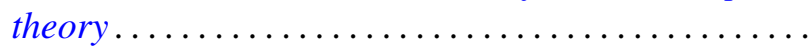

Misha Zafran, On the spectra of multipliers... 